\title{
PREVALENSI RETINOPATI DIABETIK PADA POLIKLINIK ILMU KESEHATAN MATA SELANG SATU TAHUN
}

\author{
${ }^{1}$ Tiara Ilery \\ ${ }^{2}$ Vera Sumual \\ ${ }^{3}$ Laya Rares
}

\begin{abstract}
Bagian Ilmu Kesehatan Mata Fakultas Kedokteran Universitas Sam Ratulangi Manado
Email : tiarailery@yahoo.com
\end{abstract}

\begin{abstract}
Abstrac : Diabetic retinopathy is a disease that tends to damage retinal microvasculature as chronic progressive, related with the old hyperglycaemia and also connected with diabetes mellitus and hypertension; that can expand into certain level and can turn to serious complication. The purpose of this observation is to know about prevalence of diabetic retinopathy on Polyclinic Opthalmology BLU RSU Prof. Dr. R. D. Kandou in Manado within one year. This method of observation are retrospective descriptive which is utilize the secondary data in notes form that is taken from Department of Opthalmology BLU RSU Prof. Dr. R. D. Kandou in Manado within period June 2012 - May 2013 and October 2013. In this observation that had 498 samples, with 219 people (44\%) that is positively diagnosed with diabetic retinopathy. Based from sexes it self, diabetic retinopathy occur more in female patient as much as 116 people (52,96\%). However, that disease is dominated with the patient at age 45-64 year old 128 people $(58,44 \%)$ that also has history of diabetes mellitus. From 219 patients retinopati diabetik, there are 200 people $(91,32 \%)$ that has vision problem. As we know about the risk of this disease, we are hoping that the patient of retinopati diabetik and diabetes melitus could constantly control their blood pressure and blood sugar, as well as eyes checking to cut down future risk.
\end{abstract}

Keywords : Prevalence, retinopathy, diabetic retinopathy, complication of diabetes.

Abstrak : Retinopati diabetik adalah penyakit yang berpotensi merusak pembuluh darah
retinal secara kronis progresif, berhubungan dengan hiperglikemia yang lama dan terkait
dengan diabetes melitus juga hipertensi; dapat berkembang sampai tingkatan tertentu dan
merupakan komplikasi yang serius. Tujuan penelitian adalah untuk mengetahui prevalensi
retinopati diabetik pada poliklinik ilmu kesehatan mata BLU RSU Prof. Dr. R. D. Kandou
Manado selang satu tahun. Metode penelitian bersifat deskriptif retrospektif dengan
memanfaatkan data sekunder berupa catatan medik yang terdapat di Bagian Mata BLU RSU
Prof. Dr. R. D. Kandou Manado Periode Juni 2012-Mei 2013 dan Oktober 2013. Dalam 
penelitian ini terdapat 498 sampel, dengan 219 orang (44\%) yang terdiagnosa retinopati diabetik. Berdasarkan jenis kelamin, retinopati diabetik lebih banyak dialami pasien berjenis kelamin perempuan sebanyak 116 orang (52,96\%). Sedangkan untuk rentang umur, didominasi oleh pasien dengan rentang umur 45-64 tahun sebanyak 148 orang $(67,5 \%)$, dan terdapat 128 orang $(58,44 \%)$ yang memiliki riwayat diabetes melitus. Dari 219 orang pasien retinopati diabetik terdapat 200 orang (91,32\%) yang visusnya terganggu. Dengan melihat resiko penyakit ini, pasien retinopati diabetik dan diabetes melitus diharapkan dapat mengontrol gula darah dan tekanan darah, serta dengan rutin memeriksakan mata untuk menekan progresifitas penyakit.

Kata Kunci : Prevalensi, retinopati, retinopati diabetik, komplikasi diabetes.

Retinopati diabetik adalah penyakit yang berpotensi merusak pembuluh darah retinal secara kronis progresif, berhubungan dengan hiperglikemia yang lama dan terkait dengan diabetes melitus juga hipertensi, ${ }^{1}$ dapat berkembang sampai tingkatan tertentu, ${ }^{2}$ dan merupakan komplikasi yang serius. ${ }^{3}$ Diabetes adalah penyakit gangguan metabolik dengan adanya hiperglikemia kronik dimana terjadi resistensi insulin atau gangguan sekresi yang menyebabkan komplikasi multiorgan termasuk komplikasi pada mata, ginjal, saraf, pembuluh darah, dan jantung. ${ }^{4}$ Diabetes melitus adalah masalah kesehatan utama didunia dengan angka kejadian penyakitnya yang terus meningkat tiap tahunnya. Retinopati diabetik adalah kelainan pada retina yang tidak disebabkan radang, yang ditemukan pada pasien diabetes melitus. Retinopati diabetik merupakan penyulit penyakit diabetes yang paling penting, karena insidensinya yang cukup tinggi yaitu mencapai $40-50 \%$ penderita diabetes dan prognosisnya yang kurang baik terutama bagi penglihatan. ${ }^{5}$
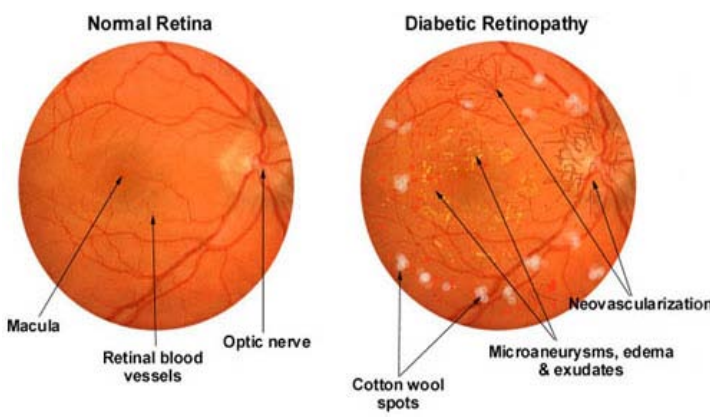

Gambar 1. (veecareeyehospital.com) Retina pada mata normal (kiri) dan retina pada mata penderita retinopati diabetik.

Sekarang ini retinopati diabetik meningkat menjadi penyebab utama kebutaan di dunia pada kelompok umur 20-65 tahun. Sekitar 2,5-50juta orang didunia mengalami kebutaan karena retinopati diabetik. Hilangnya produktifitas dan kualitas hidup membawa pasien retinopati diabetik pada masalah sosial dan ekonomi. ${ }^{6}$

Berkaitan dengan prognosis dan pengobatan, maka retinopati diabetik dibagi menjadi: ${ }^{2,4,5,7}$

1. Retinopati diabetik non proliferatif, penderita tidak mengalami gejala atau dengan gejala minimal pada fase sebelum masa dimana telah tampak lesi vaskuler melalui pemeriksaan ophtalmoskopi.

2. Retinopati diabetik proliferatif, dapat sampai pada tingkat pasien 
mengeluh melihat bayangan benda-benda hitam melayang mengikuti pergerakan mata dan penurunan tajam penglihatan.

3. Retinopati diabetik proliferatif beresiko tinggi, diidentifikasi pasien dengan retinopati diabetik yang beresiko tinggi dengan prognosis penglihatan yang buruk.

4. Edema makula diabetik, edema retina dengan tanda hilangnya gambaran retina terutama daerah makula sehingga sangat mengganggu tajam penglihatan pasien.

Gejala yang dapat dirasakan yaitu bintik-bintik gelap yang mengambang pada penglihatan, floaters, kesulitan membaca, penglihatan menjadi kabur, kesulitan dengan persepsi warna, fluktuasi, dan kehilangan daya penglihatan. ${ }^{3}$
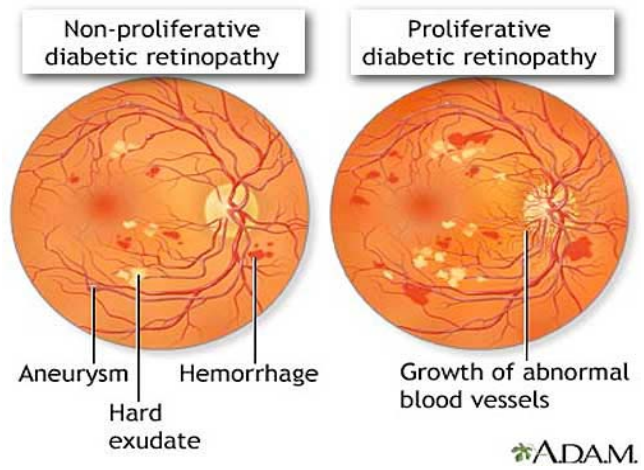

Gambar 2. (adamimages.com) Retina pada Non proliferatif retinopati diabetik (kiri) dan retina pada proliferatif retinopati diabetik (kanan).

Menurut American Academy of Opthalmology, belum diketahui sebab pasti penyakit diabetik mikrovaskuler ini. Diyakini bahwa perubahan biokimia dan fisiologi karena terpajan dengan hiperglikemia yang lama, sehingga terjadi gangguan endotel vaskuler. Kelainan hematologik dan biokimia berkorelasi dengan prevalensi dan tingkat keparahan retinopati : ${ }^{8}$

- Peningkatan adhesi platelet
- Peningkatan angregasi eritrosit

- Serum lipid yang abnormal

- Fibrinolisis yang tidak sempurna

- Abnormalnya kadar hormon pertumbuhan

- Tidak seimbangnya vascular endothelial growth factor (VEGF)

Yang menjadi faktor resiko untuk retinopati diabetik yaitu tipe diabetes yang diderita pasien, durasi diabetes penderita, kontrol gula darah, kontrol tekanan darah, kontrol lipid darah, kehamilan, dan merokok. ${ }^{1,2,4}$

Pemeriksaan penunjang untuk retinopati diabetik dapat dilakukan foto fundus dimana dapat diperiksa adanya kekeruhan pada media penglihatan, seperti pada kornea, lensa, dan badan kaca, serta fundus okuli terutama retina dan papil saraf optik, dan merupakan metode yang efektif dan sensitif, fotografi tujuh bidang merupakan pemeriksaan skrining baku emas; OCT (Optical Coherence Tomography) sangat bermanfaat dalam menentukan dan memantau edema makula, dan FFA (Fundus Flourescein Angiography) Berguna untuk menentukan kelainan mikrovaskuler pada retinopati diabetik. Defek pengisian yang besar pada jalinan kapiler menunjukan luasnya iskemia. FFA dapat membantu menentukan prognosis serta luas dan penempatan terapi laser.,

Cara penanganan utama adalah pencegahan, dengan cara mengkontrol tekanan darah, lipid darah, dan gula darah. $^{11}$ Sedangkan untuk tatalaksana retinopati diabetik dapat dilakukan Laser Scatter, untuk pasien dengan resiko tinggi retinopati diabetik proliferatif,, ${ }^{3,6,8}$ scatter panretinal photocoagulation (PRP) dapat memperlambat atau menghentikan kebocoran darah dan cairan pada retina; ${ }^{9}$ dapat diberikan anti VEGF (Vascular Endothelial Growth Factor) diantaranya Avastin (Bevacizunab) sangat efektif untuk menginhibisi neovaskularisasi yang 
berhubungan dengan retinopati diabetik yang proliferatif, glaukoma neovaskuler, edema makula diabetik, dan edema makula sekunder pada oklusi vena retina, serta Lucentis (Ranibizunab), dibuat untuk pemakaian intraokuler dengan fragmen antibody yang lebih kecil untuk penetrasi ke retina yang lebih baik. ${ }^{10}$ Untuk pembedahan, dapat dilakukan vitrektomi adalah teknik pembedahan yang dilakukan untuk mengeluarkan darah dari vitreus dengan insisi atau goresan pembedahan yang kecil. ${ }^{8}$

\section{METODOLOGI}

Metode yang diterapkan dalam penelitian ini adalah deskriptif dengan pendekatan studi retrospektif, dengan menggunakan catatan medik pasien yang berobat ke Poliklinik Ilmu Kesehatan Mata BLU RSU Prof. Dr. R. D. Kandou Manado selama periode Juni 2012-Mei 2013 dan Oktober 2013. Subjek penelitian ini adalah semua pasien retinopati diabetik dan pasien dengan riwayat diabetes melitus yang datanya lengkap. Variabel penelitian adalah pasien diabetes melitus, jenis kelamin, rentang umur, tipe retinopati, dan visus.

\section{HASIL PENELITIAN}

Penelitian dilakukan di RSU Prof. Dr. R. D. Kandou Manado pada 498 data rekam medik pasien yang datang berobat pada Poli Retina Ilmu Kesehatan Mata periode Juni 2012-Mei 2013 dan Oktober 2013. Hal-hal yang diamati yaitu jenis kelamin, usia, riwayat penyakit dahulu, diagnosa, dan visus pasien.

Tabel 1. Distribusi Pasien Berdasarkan Usia

\begin{tabular}{ccc}
\hline Usia (tahun) & $\mathrm{N}$ & Presentase (\%) \\
\hline $25-44$ & 47 & 9,4
\end{tabular}

\begin{tabular}{ccc}
$45-64$ & 334 & 67,1 \\
$>65$ & 117 & 23,5 \\
\hline Jumlah & 498 & 100,0 \\
\hline
\end{tabular}

Dapat dilihat dari tabel diatas bahwa pengelompokan pasien berdasarkan rentang usia yang paling banyak adalah pasien berusia 45-65 tahun yang lebih dari setengah dari jumlah pasien keseluruhan.

Tabel 2. Distribusi Pasien Berdasarkan Jenis Kelamin

\begin{tabular}{ccc}
\hline $\begin{array}{c}\text { Jenis } \\
\text { Kelamin }\end{array}$ & N & Presentase (\%) \\
\hline L & 231 & 46,4 \\
P & 267 & 53,6 \\
\hline Jumlah & 498 & 100,0 \\
\hline
\end{tabular}

Tabel 2 menyatakan bahwa pasien yang berjenis kelamin perempuan dan laki-laki hampir sama banyaknya, walaupun masih diungguli oleh pasien perempuan.

Tabel 3. Distribusi Pasien Berdasarkan Riwayat Penyakit Dahulunya (RPD)

\begin{tabular}{ccc}
\hline RPD & N & Presentase (\%) \\
\hline DM & 259 & 52,0 \\
DM + HP & 211 & 42,4 \\
HP & 8 & 1,6 \\
Konsul Poli & 20 & 4,0 \\
Interna & & 100,0 \\
\hline Jumlah & 498 & \\
\hline
\end{tabular}

Dari tabel 3 dapat dilihat distribusi pasien yang memeriksakan diri ke Poli Retina yang terbanyak adalah pasien dengan diabetes melitus. Pasien yang dikonsul dari Poli Interna adalah pasien-pasien yang didiagnosa diabetes melitus dan hipertensi.

Tabel 4. Distribusi Pasien Berdasarkan Diagnosa Penyakitnya

\begin{tabular}{ccc}
\hline Diagnosa & N & Presentase (\%) \\
\hline NPDR & 18 & 3,6 \\
Background NPDR & 2 & 0,4 \\
Mild NPDR & 104 & 20,9 \\
Moderate NPDR & 52 & 10,4
\end{tabular}




\begin{tabular}{|c|c|c|}
\hline \\
\hline & & \\
\hline High risk PDR & 2 & \\
\hline $\begin{array}{l}\text { Severe NPDR + } \\
\text { Moderate NPDR }\end{array}$ & 1 & \\
\hline Severe NPDR + PDR & 1 & \\
\hline PDR & 15 & \\
\hline High risk PDR & 4 & \\
\hline Advance PDR & 2 & \\
\hline NPDR + PDR & 1 & \\
\hline $\mathrm{RD}$ & 4 & \\
\hline RH & 70 & \\
\hline Lain-lain & 209 & \\
\hline Jumlah & $498-209-70=219$ & $100-42$ \\
\hline \multicolumn{3}{|c|}{$\begin{array}{l}\text { Berdasarkan tabel } 4 \text { diatas dapat kita lihat } \\
\text { bahwa dari } 498 \text { pasien, presentase terbesar } \\
\text { adalah pasien yang mengalami penyakit } \\
\text { lain bukan retinopati sebanyak } 209 \text { orang } \\
\text { (42\%), dan dari penyakit Retinopati } \\
\text { Diabetik yang terbanyak adalah mild } \\
\text { NPDR (retinopati diabetik non proliferatif } \\
\text { ringan) sebanyak } 104 \text { orang (20,9\%). }\end{array}$} \\
\hline \multicolumn{3}{|c|}{$\begin{array}{l}\text { Tabel 5. Distribusi Pasien Berdasarkan } \\
\text { Status Visusnya }\end{array}$} \\
\hline Status Visus & $\begin{array}{r}\text { Prese } \\
(\%\end{array}$ & \\
\hline Terganggu & 433 & \\
\hline $\begin{array}{c}\text { Tidak } \\
\text { Terganggu }\end{array}$ & 65 & \\
\hline Total & 498 & \\
\hline
\end{tabular}

Dari tabel 5 diketahui pasien-pasien yang mengalami gangguan penglihatan lebih banyak daripada pasien-pasien yang ketajaman penglihatannya tidak terganggu walaupun mengalami Retinopati Diabetik.

Tabel 6. Distribusi Pasien Berdasarkan Jenis Kelamin dan Riwayat Penyakit Dahulu

\begin{tabular}{ccccc}
\hline \multirow{2}{*}{$\begin{array}{c}\text { Jenis } \\
\text { Kelamin }\end{array}$} & \multicolumn{4}{c}{ Riwayat Penyakit Dahulu } \\
DM & $\begin{array}{c}\text { DM } \\
+ \text { HP }\end{array}$ & HP & $\begin{array}{c}\text { Konsul } \\
\text { P.Int }\end{array}$ \\
\hline L & 125 & 97 & 3 & 6 \\
P & 134 & 114 & 5 & 14 \\
\hline
\end{tabular}

Dapat dilihat pada tabel diatas bahwa pasien yang mempunyai riwayat penyakit diabetes melitus adalah yang paling banyak mengalami Retinopati Diabetik, dan presentasi yang paling sedikit yaitu pasien yang diketahui mempunyai riwayat hipertensi.

Tabel 7. Distribusi Pasien Berdasarkan Jenis Kelamin dan Diagnosa

\begin{tabular}{|c|c|c|}
\hline \multirow{2}{*}{ Diagnosa } & \multicolumn{2}{|c|}{ Jenis Kelamin } \\
\hline & $\mathrm{L}$ & $\mathrm{P}$ \\
\hline NPDR & 7 & 11 \\
\hline Background NPDR & 1 & 1 \\
\hline Mild NPDR & 51 & 53 \\
\hline Moderate NPDR & 25 & 27 \\
\hline Severe NPDR & 5 & 8 \\
\hline $\begin{array}{c}\text { Severe NPDR + } \\
\text { High risk PDR }\end{array}$ & 2 & 0 \\
\hline $\begin{array}{l}\text { Severe NPDR + } \\
\text { Moderate NPDR }\end{array}$ & 0 & 1 \\
\hline Severe NPDR + PDR & 1 & 0 \\
\hline PDR & 7 & 8 \\
\hline High risk PDR & 1 & 3 \\
\hline Advance PDR & 1 & 1 \\
\hline NPDR + PDR & 1 & 0 \\
\hline $\mathrm{RD}$ & 1 & 3 \\
\hline $\mathrm{RH}$ & 34 & 36 \\
\hline Lain-lain & 94 & 115 \\
\hline Jumlah & $\begin{array}{l}231-94- \\
34=103\end{array}$ & $\begin{array}{c}267-115- \\
36=116\end{array}$ \\
\hline
\end{tabular}

Tabel 7 memperlihatkan bahwa perbandingan diagnosa penyakit untuk pasien berjenis kelamin perempuan dan laki-laki hampir sama untuk penyakit Retinopati Diabetik.

Tabel 8. Distribusi Pasien Berdasarkan Jenis kelamin dan Status Visus

\begin{tabular}{ccc}
\hline $\begin{array}{c}\text { Jenis } \\
\text { Kelamin }\end{array}$ & \multicolumn{2}{c}{ Status Visus } \\
Terganggu & $\begin{array}{c}\text { Tidak } \\
\text { Terganggu }\end{array}$ \\
\hline L & 198 & 33 \\
$\mathrm{P}$ & 235 & 32 \\
\hline
\end{tabular}

Tabel 8 menyatakan bahwa terdapat perbedaan yang cukup jauh antara pasien yang visusnya terganggu dan yang tidak 
terganggu baik untuk pasien berjenis kelamin perempuan maupun berjenis kelamin laki-laki.

Tabel 9. Distribusi Pasien Berdasarkan Usia dan Riwayat Penyakit Dahulu

\begin{tabular}{ccccc}
\hline \multirow{2}{*}{$\begin{array}{c}\text { Usia } \\
\text { (tahun) }\end{array}$} & \multicolumn{4}{c}{ Riwayat Penyakit Dahulu } \\
& DM & DM & HP & $\begin{array}{c}\text { Konsul } \\
\text { P.Int }\end{array}$ \\
\hline $25-44$ & 32 & 13 & 0 & 2 \\
$45-64$ & 174 & 139 & 6 & 15 \\
$>65$ & 53 & 59 & 2 & 3 \\
\hline
\end{tabular}

Tabel 9 menyatakan bahwa distribusi pasien yang mempunyai riwayat diabetes melitus presentasinya terbanyak, dengan berada pada rentang usia 45-64 tahun.

Tabel 10. Distribusi Pasien Berdasarkan Usia dan Diagnosa

\begin{tabular}{cccc}
\hline \multirow{2}{*}{ Diagnosa } & \multicolumn{3}{c}{ Rentang Usia (tahun) } \\
& $25-44$ & $45-64$ & $>65$ \\
\hline NPDR & 1 & 11 & 6 \\
Background NPDR & 0 & 2 & 0 \\
Mild NPDR & 8 & 65 & 31 \\
Moderate NPDR & 5 & 36 & 11 \\
Severe NPDR & 2 & 9 & 2 \\
Severe NPDR + & 0 & 2 & 0 \\
High risk PDR & & & \\
Severe NPDR + & 0 & 1 & 0 \\
Moderate NPDR & & & \\
Severe NPDR + & 0 & 0 & 1 \\
PDR & 0 & 12 & 3 \\
PDR & 1 & 3 & 0 \\
High risk PDR & 0 & 2 & 0 \\
Advance PDR & 0 & 1 & 0 \\
NPDR + PDR & 0 & 4 & 0 \\
RD & 3 & 44 & 23 \\
RH & 27 & 142 & 40 \\
Lain-lain & $47-27-$ & $334-142-$ & $117-40-$ \\
Jumlah & $3=\mathbf{1 7}$ & $44=\mathbf{1 4 8}$ & $23=\mathbf{5 4}$ \\
\hline
\end{tabular}

Diketahui dari tabel 10 bahwa yang terbanyak distribusi pasiennya adalah pada rentang usia 45-64 tahun. Terdapat perbedaan jumlah yang lumayan menonjol antara 3 rentang usia diatas.

Tabel 11. Distirbusi Pasien Berdasarkan Riwayat Penyakit Dahulu dan Diagnosa

\begin{tabular}{ccccc}
\hline & M & & + & P.Int \\
& & & HP & \\
\hline NPDR & 9 & 0 & 8 & 1 \\
Background & 0 & 0 & 1 & 1 \\
NPDR & 56 & 2 & 41 & 5 \\
Mild NPDR & 35 & 1 & 9 & 7 \\
Moderate NPDR & 9 & 0 & 2 & 2 \\
Severe NPDR & & 0 & 2 & 0 \\
Severe NPDR + & 0 & & & \\
High risk PDR & & 0 & 0 & 0 \\
Severe NPDR + & 1 & & & \\
Moderate NPDR & & 0 & 0 & 0 \\
Severe NPDR + & 1 & 2 & 4 & 0 \\
PDR & 9 & 0 & 1 & 0 \\
PDR & 3 & 0 & 0 & 0 \\
High risk PDR & 2 & 0 & 1 & 0 \\
Advance PDR & 0 & 0 & 1 & 0 \\
NPDR + PDR & 3 & 0 & 52 & 2 \\
RD & 16 & 3 & 89 & 2 \\
RH & 115 & & &
\end{tabular}

Dari tabel 11 dapat dilihat distribusi pasien dengan riwayat penyaki diabetes melitus, hipertensi, gabungan keduanya, serta yang dikonsul dari Poli Interna pada masingmasing diagnosa; dengan distribusi terbanyak adalah pasien yang mempunyai riwayat penyakit dahulu diabetes melitus, dan diagnosa mild NPDR.

Tabel 12. Distribusi Pasien berdasarkan Diagnosa dan Status Visus

\begin{tabular}{ccc}
\hline Diagnosa & \multicolumn{2}{c}{ Status Visus } \\
& Terganggu & $\begin{array}{c}\text { Tidak } \\
\text { Terganggu }\end{array}$ \\
\hline NPDR & 17 & 1 \\
Background & 1 & 1 \\
NPDR & 95 & 9 \\
Mild NPDR & 95 & 6 \\
Moderate & 46 & 0 \\
NPDR & 13 & \\
$\begin{array}{c}\text { Severe NPDR } \\
\text { Severe NPDR }\end{array}$ & & \\
+ High risk & 2 & \\
PDR & & 0 \\
$\begin{array}{c}\text { Severe NPDR } \\
+ \text { Moderate } \\
\text { NPDR }\end{array}$ & 1 & 0 \\
Severe NPDR & & 1 \\
+ PDR & 1 & \\
PDR & 14 &
\end{tabular}




\begin{tabular}{ccc} 
High risk & 4 & 0 \\
PDR & & 0 \\
Advance & 2 & \\
PDR & & 0 \\
NPDR + & 1 & 1 \\
PDR & 3 & 10 \\
RD & 60 & 36 \\
RH & 173 & $65-36-$ \\
Lain-lain & $433-173-$ & $10=\mathbf{1 9}$ \\
\hline \multirow{2}{*}{ Jumlah } & $60=\mathbf{2 0 0}$ & \\
\hline
\end{tabular}

Tabel 12 memperlihatkan bahwa pasien dengan diagnosa Retinopati Diabetik dengan tipe apapun mengalami gangguan ketajaman penglihatan dengan jumlah yang relatif lebih banyak dibanding dengan yang tisak terganggu.

Keterangan :

1. $\mathrm{L}=\mathrm{Laki}=$ laki

2. $\mathrm{P}=$ Perempuan

3. NPDR $=$ Retinopati diabetik non proliferatif

4. Background NPDR = Retinopati diabetik non proliferatif awal

5. Mild NPDR = Retinopati diabetik non proliferatif ringan

6. Moderate NPDR $=$ Retinopati diabetik non proliferatif sedang

7. Severe NPDR = Retinopati diabetik non proliferatif berat

8. PDR $=$ Retinopati diabetik proliferatif

9. High risk PDR = Retinopati diabetik proliferatif beresiko tinggi

10. Advance PDR = Retinopati diabetik proliferatif berat

11. $\mathrm{RD}=$ Retinopati diabetik

12. $\mathrm{RH}=$ Retinopati hipertensi

13. $\mathrm{DM}=$ Diabetes melitus

14. $\mathrm{HP}=$ Hipertensi

15. Konsul P.Int $=$ Konsul poli interna

\section{PEMBAHASAN}

Berdasarkan hasil penelitian yang dilakukan dengan kriteria sampel yaitu pasien Retinopati Diabetik yang tercatat dalam laporan rekam medik sebanyak 498 orang pada periode Juni 2012-Mei 3013 dan Oktober 2013, diperoleh jumlah pasien 219 orang (44\%).

Berdasarkan jenis kelamin, diperoleh hasil bahwa pasien Retinopati Diabetik yang berjenis kelamin perempuan berjumlah 116 orang dan yang berjenis kelamin laki-laki berjumlah 103 orang. Hasil ini tidak berbeda dengan hasil penelitian yang dilakukan oleh National Eye Intitute $(2010)^{11}$, dimana didapatkan pasien yang berjenis kelamin perempuan lebih banyak terkena retinopati diabetik dibandingkan dengan pasien laki-laki. Didukung juga dengan teori-teori yang menjelaskan bahwa setelah berumur diatas 40 tahun, metabolisme dan struksturstruktur sel sudah lebih susah beradaptasi dan bekerja lebih lambat, apalagi setelah menopause adanya hubungan dengan tidak seimbangnya hormon estrogen dan progesteron, ditambah kehamilan menjadi salah satu faktor resiko pada pasien yang menderita diabetes dan retinopati diabetik. Tetapi berbeda dengan hasil Jordan University Hospital (Digital Journal Ophtalmology, 2008) ${ }^{12}$, dimana diperoleh pasien yang berjenis kelamin laki-laki lebih banyak dibanding dengan pasien berjenis kelamin perempuan. Namun data ini tidak bisa menjelaskan dengan pasti hubungan jenis kelamin dengan penyakit Retinopati Diabetik, karena tidak lengkapnya data pada rekam medik sehingga tidak semua pasien bisa diambil datanya untuk diteliti.

Berdasarkan rentang usia, diperoleh hasil bahwa pasien Retinopati Diabetik yang terbanyak adalah pada rentang usia 45-64 tahun sebanyak 148 orang (67,5\%). Hasil ini berbeda dengan hasil penelitian yang dilakukan oleh Natinal Eye Institute $(2010)^{16}$ dimana didapatkan hasil lebih banyak pada rentang usia diatas 65 tahun. Dan berbeda dengan hasil penelitian Jordan University Hospital (Digital Journal Ophtalmology, 2008) ${ }^{17}$ bahwa pasien dibawah 45 tahun tidak bermanifestasikan severe NPDR, sedangkan pada penelitian ini didapatkan 2 
pasien severe NPDR dan 1 pasien dengan high risk $P D R$.

Berdasarkan riwayat penyakit dahulu, diperoleh hasil bahwa presentase terbesar riwayat penyakit dahulu yang dialami oleh pasien retinopati diabetik adalah diabetes melitus, diikuti gabungan diabetes melitus dan hipertensi, lalu pasien yang dikonsul dari poli interna. Sesuai teori bahwa pasien diabetes melitus sangat beresiko terhadap penyakit retinopati diabetik.

Berdasarkan diagnosa pasien, diperoleh hasil bahwa presentase terbesar yang dialami pasien retinopati bila diklasifikasikan adalah mild NPDR.

Berdasarkan status visusnya, diperoleh hasil bahwa lebih banyak pasien yang visusnya terganggu dibandingkan dengan yang tidak terganggu. Hasil yang diperoleh ini sesuai dengan teori yang menjelaskan bahwa gula darah sangat berhubungan dengan cairan dalam bola mata. Sehingga bila pasien yang sudah diabetes dan terkena Retinopati Diabetik, sangatlah mungkin cepat atau lambat penglihatannya akan terganggu atau memburuk. Namun hasil ini akan lebih jelas menjelaskan dampak Retinopati Diabetik pada pasien bila diteliti juga durasi penyakitnya. Tetapi karena tidak lengkapnya data rekam medik, sehingga tidak bisa dicari hubungan durasi penyakitnya dengan memburuknya visus pasien.

\section{KESIMPULAN}

Hasil penelitian pada pasien Retinopati Diabetik pada Poliklinik Ilmu Kesehatan Mata BLU RSU Prof. Dr. R. D. Kandou Manado, dapat diambil kesimpulan bahwa terdapat pasien retinopati diabetik yang berjenis kelamin perempuan lebih banyak daripada pasien berjenis kelamin lelaki, Mild NPDR merupakan stadium Retinopati Diabetik yang paling banyak ditemukan, ditemukan pasien Retinopati Diabetik banyak mengalami gangguan visus, yang paling banyak mengalami retinopati diabetik adalah pasien yang mempunyai riwayat diabetes melitus, yang paling banyak mempunyai riwayat diabetes melitus adalah pasien dengan usia 45-64 tahun, dan yang paling banyak mengalami gangguan visus adalah pasien yang berjenis kelamin perempuan.

\section{SARAN}

Untuk peneliti yang akan datang yang ingin melakukan penelitian tentang Retinopati Diabetik, agar menggali informasi tentang hubungannya dengan durasi penyakit, kehamilan, serta kebiasaan merokok. Untuk populasi penderita Retinopati Diabetik, diharapkan dapat mengontrol gula darah dan tekanan darah, serta dengan rutin memeriksakan mata untuk menekan progresifitas penyakit.

\section{DAFTAR PUSTAKA}

1. Bailey C, Chakravarthy U, Cohen S, Dodson P, Gibson J, Menon G, dkk. Diabetic Retinopathy Guidelines. The Royal College of Opthalmologists.2012;6-9,56-64.

2. Chew EY, Benson WE, Blodi BA, Boldt HC, Murray TG, Olsen TW, dkk. Diabetic retinopathy. Preferred practice pattern.2012;4:4-15.

3. Kumar KPS, Bhowmik D, Harish G, Duraivel S, Kumar BP. Diabetic Retinopathy - Symptoms, Causes, Risk Factors and Treatment. The Pharma Innovation.2012;1(8):7-13.

4. Mitchell P, Foran S, Wong TY, Chua B, Patel I, Ojaimi E. Guidelines for the Management of Diabetic Retinopathy. Government : National Health and Medical Research Council (NHMRC).2008;22-4,30-6.

5. Ilyas HS, Yulianti SR. Penglihatan turun perlahan tanpa mata merah. In: Ilyas HS, Yulianti SR (eds.)Ilmu Penyakit Mata. 4th ed. Jakarta: Badan Penerbit FKUI; 2012. p221-5.

6. Viswanath K, McGavin DDM. Diabetic Retinopathy : Clinical 
findings and management. Journal of Community Eye Health.2003;16(46):21-4.

7. Antonetti DA, Klein R, Gardner TW. Mechanisms of Disease Diabetic Retinopathy. The New England Journal of Medicine.2012;366:122739.

8. Regillo C, Chang TS, Johnson MW, Kaiser PK, Scott IU, Spaide R, dkk. Basic and Clinical Science Course : Retina and Vitreous. American Academy of Opthalmology.2005;12:99-118.

9. Riordan-Eva P, Whitcher JP. Retina. In: Susanto D (eds.)Vaughan \& Asbury : Oftalmologi Umum. 17th ed. Jakarta: EGC; 2012. p185-93.

10. Gupta N, Mansoor S, Sharma A, Sapkal A, Sheth J, Falatoonzadeh P, dkk. Diabetic Retinopathy and VEGF. The Open Ofthalmology Journal.2013;7:4-10.

11. National Eye Institute. Diabetic Retinopathy.

www.nei.nih.gov/eyedata/diabetic.asp (accessed 19 Januari 14).

12. Digital Journal of Opthalmology. Prevalence and risk factors of diabetic retinopathy among Jordanian patients with type 2 diabetes.

http://www.djo.harvard.edu/site.php?u $\mathrm{rl}=/$ physicians/oa/1204 (accessed 19 Januari 14). 